\title{
Stereotactic Radiosurgery Practice Patterns for Brain Metastases in the United States: A National Survey
}

\author{
Erik S Blomain \\ Thomas Jefferson University \\ Hyun Kim, MD \\ Thomas Jefferson University \\ Shivank Garg \\ Thomas Jefferson University \\ Deepak Bhamidipati \\ Thomas Jefferson University \\ Jenny Guo \\ Thomas Jefferson University
}

Follow this and additional works at: https://jdc.jefferson.edu/jhnj

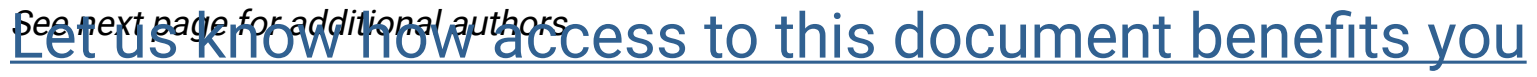

\section{Recommended Citation}

Blomain, Erik S; Kim, MD, Hyun; Garg, Shivank; Bhamidipati, Deepak; Guo, Jenny; Kalchman, Ingrid; McAna, John F.; and Shi, Wenyin (2018) "Stereotactic Radiosurgery Practice Patterns for Brain Metastases in the United States: A National Survey," JHN Journal: Vol. 13 : Iss. 1 , Article 6.

DOI: https://doi.org/10.29046/JHNJ.013.1.006

Available at: https://jdc.jefferson.edu/jhnj/vol13/iss1/6

This Article is brought to you for free and open access by the Jefferson Digital Commons. The Jefferson Digital Commons is a service of Thomas Jefferson University's Center for Teaching and Learning (CTL). The Commons is a showcase for Jefferson books and journals, peer-reviewed scholarly publications, unique historical collections from the University archives, and teaching tools. The Jefferson Digital Commons allows researchers and interested readers anywhere in the world to learn about and keep up to date with Jefferson scholarship. This article has been accepted for inclusion in JHN Journal by an authorized administrator of the Jefferson Digital Commons. For more information, please contact: JeffersonDigitalCommons@jefferson.edu. 
Stereotactic Radiosurgery Practice Patterns for Brain Metastases in the United States: A National Survey

\section{Authors}

Erik S Blomain; Hyun Kim, MD; Shivank Garg; Deepak Bhamidipati; Jenny Guo; Ingrid Kalchman; John F. McAna; and Wenyin Shi 


\section{Stereotactic Radiosurgery Practice Patterns for Brain Metastases in the United States: A National Survey}

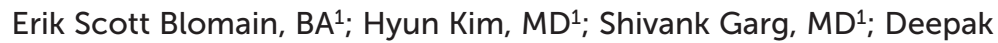

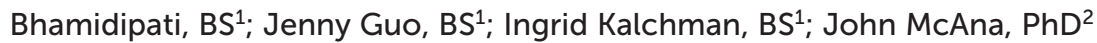 \\ and Wenyin Shi, MD, PhD ${ }^{1}$ \\ ${ }^{1}$ Department of Radiation Oncology, Thomas Jefferson University, Sidney Kimmel Cancer
Center at Jefferson, Philadelphia, PA
2 Jefferson College of Population Health, Thomas Jefferson University, Philadelphia, PA
}

\section{Running Title}

Brain metastases SRS use practice

\section{Conflict of Interest Notification \\ No actual or potential conflicts of interest.}

\section{Acknowledgements}

E.S.B. received an F30 Ruth Kirschstein MD-PhD Fellowship Award (CA180500).

\begin{abstract}
Background: Stereotactic radiosurgery (SRS) has emerged as an important modality for the treatment of intracranial metastases. There are currently few established guidelines delineating indications for SRS use and fewer still regarding plan evaluation in the treatment of multiple brain metastases.

Methods: An 18 question electronic survey was distributed to radiation oncologists at National Cancer Institute ( $\mathrm{NCl}$ ) designated cancer centers in the US (60). Centers without radiation oncologists were excluded. Physicians who indicated that they do not prescribe SRS were excluded from the remaining survey questions. Sign test and Chi-square test were used to determine if responses differed significantly from random distribution.
\end{abstract}

Results: 116 of the 697 radiation oncologists surveyed completed the questionnaire, representing 51 institutions. $62 \%$ reported treating patients with brain metastases using SRS. Radiation oncologists prescribing SRS most commonly treat CNS (66.2\%) and lung (49.3\%) malignancies. SRS was used more frequently for $<10$ brain metastases $(73.7 \%$; $\mathrm{p}<.0001)$ and whole brain radiation therapy (WBRT) for $>10$ brain metastases $(82.5 \%$; $\mathrm{p}<.0001)$. The maximum number of lesions physicians were willing to treat with SRS without WBRT was 1-4 (40.4\%) and 5-10 (42.4\%) ( $p<.0001$ compared to 11-15, 16-20 and no limit). The most important criteria for choosing SRS or WBRT were number of lesions $(p<.0001)$ and performance status $(p=.016)$. The most common margin for SRS was $0 \mathrm{~mm}$ (49.1\%; $p=.0021)$. The most common dose constraints other than critical structure was conformity index (84.2\%) and brain V12 (61.4\%). The LINAC was the most common treatment modality (54.4\%) and mono-isocenter technique for multiple brain metastases was commonly used $(43.9 \% ; p=.23)$. Most departments do not have a policy for brain metastases treatment $(64.9 \% ; p=.024)$.

Conclusions: This is one of the first national surveys assessing the use of SRS for brain metastases in clinical practice. These data highlight some clinical considerations for physicians treating brain metastases with SRS.

Summary: This is among the first national surveys to assess the use of SRS for brain metastases in clinical practice. Specifically, radiation oncologist reported increasingly using SRS instead of WBRT for treating $<10$ metastases, with the LINAC being the most common modality. Further, treatment parameters considered the most important included $0 \mathrm{~mm}$ margins, conformity index, brain V12, and monoisocenter technique for multiple brain metastases. These results may provide context regarding the use of SRS for brain metastases in clinical practice.

\section{INTRODUCTION}

Brain metastases are a significant cause of morbidity and mortality among oncologic patients, affecting 20-40\% of this population. ${ }^{1}$ Several therapeutic strategies for intracranial metastases exist, including stereotactic radiosurgery (SRS), whole brain radiotherapy (WBRT), surgical resection and supportive care with steroids, though systemic therapy remains an option for patients with selected cancers. ${ }^{2}$ WBRT was historically the treatment modality of choice for brain metastases with or without surgical resection. ${ }^{3,4}$ Technological improvements in Gamma Knife and LINAC-based SRS coupled with data indicating decreased cognitive toxicity with SRS5, have led to increased utilization of SRS6. Although evidence-based clinical practice guidelines exist for the use of SRS for brain metastases, $^{7-12}$ there are comparatively fewer reports that study specific aspects of SRS plan evaluation or if current use reflects the recommendations of professional societies. In that context, the current study represents one of the few national surveys which specifically investigates these issues to clarify the role of SRS for intracranial metastases in clinical practice.

\section{MATERIALS AND METHODS}

\section{Study Design}

An 18 question, non-incentivized electronic survey was distributed to radiation oncologists at National Cancer Institute 
designated cancer centers in the United States (60). Centers without radiation oncologists were excluded. The total number of physicians contacted was 697. Physicians who reported not prescribing SRS were not invited to complete remaining survey questions. Per institutional policy, this study was IRB-exempt.

\section{Statistical Analysis}

Depending on type of question, 95\% confidence interval (estimate of proportion), sign test (difference from expected mean) or Chi-square test (difference from expected distribution) were used to determine if responses differed significantly from random distribution. All data analyses were completed using Stata software and a $P$ value $<0.05$ was considered to be statistically significant.

\section{RESULTS}

\section{Response and Demographic Data}

All survey results are reproduced in Table 1. Of 697 physicians surveyed, 118 $(16.9 \%)$ responded, with $28.7 \%$ reporting that they do not treat brain metastases with SRS. Respondents represented 51 different institutions across 28 states with varying years of practice experience.

\section{Indications and Use in Practice}

Respondents primarily treated CNS (66.2\%, $95 \% \mathrm{Cl}$ [54-77\%]); lung was numerically the second most commonly treated disease site (49.3\%). SRS (73.7\%) was used more frequently than WBRT $(10.5 \%)$ for $<10$ brain metastases $(p<.0001)$ while WBRT $(82.5 \%)$ was used more frequently than SRS $(5.3 \%)$ for $>=10$ brain metastases $(p<.0001)$. The maximum number of lesions physicians were willing to treat with SRS without WBRT in the treatment session was 1-4 (40.4\%) and 5-10 (42.4\%) ( $p<.0001$; compared to $11-15,16-20$ and no limit). Most physicians reported they would not treat more than 10 lesions over multiple sessions with SRS $(43.9 \%$; $p=.0003$ ) but $19.3 \%$ reported there was no limit to the number they would treat. Physicians indicated that their practice had changed in the past 5 years by more frequently using SRS without WBRT (84.2\%) and SRS without other treatments (i.e. surgery or WBRT; $82.5 \%$ ). Criteria used to determine SRS versus WBRT use were number of lesions ( $p<.0001)$, histology $(p=.0014)$, performance status $(p=.016)$ and location $(p<.0001)$ as determined by sign-test. Leptomeningeal disease was statistically significant versus all other choices as the predominant contraindication to prescribing SRS without WBRT (93\%; Cl [83-98\%]).

\section{Treatment Modality and Planning}

LINAC (54.4\%) was more commonly used than the CyberKnife (14.0\%) or Gamma Knife (31.6\%) for SRS treatment $(p=.0009)$. The mono-isocenter technique for multiple brain metastases was commonly used (43.9\%; $p=.23)$. The most common margin for SRS was $0 \mathrm{~mm}$ (49.1\%; $p=.0021$ ), with $38.6 \%$ and $12.3 \%$ prescribing a $1 \mathrm{~mm}$ and $2 \mathrm{~mm}$ margin, respectively. The most common dose constraints other than critical structure were conformity index (84.2\%) and V12 (61.4\%). Diameter, volume and histology of lesion were all ranked as significant in determining the SRS prescription dose (sign-test, $p<.0001, p=.001$ and $\mathrm{p}<.0001$, respectively). Notably, most departments do not have a policy in place for treating brain metastases with SRS (64.9\%; $p=.024)$.

\section{DISCUSSION}

Despite increasing use of SRS to treat brain metastases, little exists in terms of guidance for physicians using this modality. Moreover, our data indicate that most departments do not have policies governing SRS use. Importantly, no clear guidelines exist regarding the maximum number of metastases for which SRS is recommended, despite a historicallyused cutoff of 4 in clinical trials. 5,13,14 In this study, $42.4 \%$ of respondents reported using SRS for patients with 5-10 metastases and $17.5 \%$ of respondents offering it for more than 10 lesions without WBRT. Thus, a significant number of respondents are using SRS for more than the standard 4 lesions. In total, $73.7 \%$ of respondents reported using SRS more often for $<10$ metastasis, and $82.5 \%$ used WBRT more often for $>10$ lesions. These physicians may be influenced by a shifting paradigm towards SRS alone for a greater than 5 or greater than 10 lesions. ${ }^{15-17}$ Indeed, the majority of respondents reported increasing their use of SRS over the last five years. While the survey did not evaluate the role insurers play in physicians' decision making, private insurance typically recognizes the role of SRS in treating multiple brain metastases with no clear maximum identified. ${ }^{18}$ Additionally, citing a growing body of literature regarding safety and efficacy, current National Comprehensive Cancer Network (NCCN) recommendations for SRS alone do not specify a maximum number of lesions. ${ }^{19}$

Knisely et al first examined the use of SRS in clinical practice several years ago; physicians at two conferences hosted by national stereotactic radiosurgery societies were asked to fill a questionnaire, with a majority of respondents considering it "reasonable" to treat greater than 5 metastases with SRS alone. ${ }^{20}$ More recently, Sandler et al evaluated practicing physicians' "cutoff" for treating brain metastases with SRS alone versus WBRT, among other scenarios. ${ }^{21}$ Importantly, they found CNS-specialists to be comfortable treating a mean of 8.1 lesions compared to 5.6 and 5.1 lesions for low-volume CNS specialists and non-CNS specialists respectively. ${ }^{21}$ While our survey did not stratify SRS use according to specialization, our results reflect a similar trend among physicians at a national level for treating greater than five lesions with SRS alone.

Notably, recent American Society for Therapeutic Radiology and Oncology (ASTRO) Choosing Wisely guidelines recommend against using adjuvant WBRT with SRS, and instead recommend SRS monotherapy for brain metastases. ${ }^{12,22}$ However, no guidance is provided regarding the SRS plan evaluation. The present study identifies several parameters in current SRS use for brain metastasis in practice, including the use of $0 \mathrm{~mm}$ margins, conformity index, brain V12, and the mono-isocenter technique for multiple brain metastases. While our survey did not specifically assess the values used for each parameter, retrospective data indicate that V12 greater than $10.9 \mathrm{~cm} 3$ is associated with a $51 \%$ 1 year risk of radionecrosis. ${ }^{23}$ Likewise, other treatment parameters appear to play an important role in the development of a safe and effective treatment plan.

The overall response rate was low for this study, introducing the potential for 
response bias. Despite this potential limitation, emerging research suggests that low response rates are not inherently associated with inaccurate results or nonresponder bias. 24,25 Moreover, the wide geographic spread and distribution of practice experience among respondents suggests that the current sample was representative of the academic field at large. As this survey was distributed to physicians practicing at $\mathrm{NCl}$-designated cancer centers however, the responses may not be reflective of the patterns of SRS use in private practice. Another potential limitation of the survey was that it did not account for patient volume per institution, which may be a surrogate for expertise in SRS and could influence aggressiveness in treating multiple brain metastases. Furthermore, individual practitioners were not asked about their patient volumes, which may be a surrogate for clinical versus research time in an academic setting and therefore influence management preferences. Future studies will be needed to continue to address these issues and refine clinical practice.

\section{CONCLUSIONS}

To our knowledge, this is among the first national assessments of the use of SRS for brain metastases in clinical practice in the U.S. The data indicate that radiation oncologists are increasingly using SRS for the treatment of intracranial lesions, even in situations which were historically treated with WBRT. Treatment parameters considered most by respondents include $0 \mathrm{~mm}$ margins, conformity index, brain V12, and a mono-isocenter technique for multiple brain metastases. These data may reveal areas that require guidance and instruction from cooperative group committees.

\section{REFERENCES}

1. Mehta MP, Tsao MN, Whelan TJ, et al. The American Society for Therapeutic Radiology and Oncology (ASTRO) evidencebased review of the role of radiosurgery for brain metastases. International Journal of Radiation Oncology, Biology, Physics 2005;63(1):37-46. doi: 10.1016/j. ijrobp.2005.05.023
2. Shonka N, Venur VA, Ahluwalia MS. Targeted Treatment of Brain Metastases. Current Neurology and Neuroscience Reports 2017;17(4):37. doi: 10.1007/s11910-0170741-2

3. Patchell RA, Tibbs PA, Regine WF, et al. Postoperative radiotherapy in the treatment of single metastases to the brain: a randomized trial. Jama 1998;280(17):1485-9.

4. Patchell RA, Tibbs PA, Walsh JW, et al. A randomized trial of surgery in the treatment of single metastases to the brain The New England Journal of Medicine 1990;322(8):494-500. doi: 10.1056/ NEJM199002223220802

5. Chang EL, Wefel JS, Hess KR, et al. Neurocognition in patients with brain metastases treated with radiosurgery or radiosurgery plus whole-brain irradiation: a randomised controlled trial. Lancet Oncol 2009;10(11):1037-44. doi: 10.1016/S14702045(09)70263-3

6. Lippitz B, Lindquist C, Paddick I, et al Stereotactic radiosurgery in the treatment of brain metastases: the current evidence. Cancer Treatment Reviews 2014;40(1):48-59. doi: 10.1016/j.ctrv.2013.05.002

7. Tsao MN, Rades D, Wirth A, et al. Radiotherapeutic and surgical management for newly diagnosed brain metastasis(es): An American Society for Radiation Oncology evidence-based guideline. Practical Radiation Oncology 2012;2(3):210-25. doi: 10.1016/j.prro.2011.12.004

8. Gaspar LE, Mehta MP, Patchell RA, et al. The role of whole brain radiation therapy in the management of newly diagnosed brain metastases: a systematic review and evidence-based clinical practice guideline. Journal of Neuro-Oncology 2010;96(1):1732. doi: 10.1007/s11060-009-0060-9

9. Kalkanis SN, Kondziolka D, Gaspar LE, et al. The role of surgical resection in the management of newly diagnosed brain metastases: a systematic review and evidence-based clinical practice guideline. Journal of neurooncology 2010;96(1):33-43. doi: 10.1007/ s11060-009-0061-8

10. Mehta MP, Paleologos NA, Mikkelsen T, et al The role of chemotherapy in the management of newly diagnosed brain metastases: a systematic review and evidence-based clinical practice guideline. Journal of NeuroOncology 2010;96(1):71-83. doi: 10.1007/ s11060-009-0062-7

11. Linskey ME, Andrews DW, Asher AL, et al. The role of stereotactic radiosurgery in the management of patients with newly diagnosed brain metastases: a systematic review and evidence-based clinical practice guideline. Journal of Neuro-Oncology 2010;96(1):45-68. doi: 10.1007/s11060-0090073-4
12. ASTRO. ChoosingWisely. ASTRO releases second list of five radiation oncology treatments to question, as part of national Choosing Wisely campaign. Choosing Wisely 2014

13. Aoyama H, Shirato H, Tago M, et al. Stereotactic radiosurgery plus whole-brain radiation therapy vs stereotactic radiosurgery alone for treatment of brain metastases: a randomized controlled trial. Jama 2006;295(21):2483-91. doi: 10.1001/Jama. 295.21.2483

14. Kocher M, Soffietti R, Abacioglu U, et al. Adjuvant whole-brain radiotherapy versus observation after radiosurgery or surgical resection of one to three cerebral metastases: results of the EORTC 22952-26001 study. Journal of Clinical Oncology: Official Journal of the American Society of Clinical Oncology 2011;29(2):134-41. doi: 10.1200/ JCO.2010.30.1655

15. Yamamoto M, Serizawa T, Shuto T, et al. Stereotactic radiosurgery for patients with multiple brain metastases (JLGK0901): a multi-institutional prospective observational study. Lancet Oncol 2014;15(4):387-95. doi: 10.1016/S1470-2045(14)70061-0

16. Rava P, Leonard K, Sioshansi S, et al. Survival among patients with 10 or more brain metastases treated with stereotactic radiosurgery. Journal of Neurosurgery 2013;119(2):457-62. doi: 10.3171/2013.4.JNS121751

17. Yamamoto M, Kawabe $T$, Sato $Y$, et al. Stereotactic radiosurgery for patients with multiple brain metastases: a case-matched study comparing treatment results for patients with 2-9 versus 10 or more tumors. Journal of Neurosurgery 2014;121 Suppl:1625. doi: 10.3171/2014.8.GKS141421

18. Shield BCB. Stereotactic Radiosurgery (SRS) and Stereotactic Body Radiation Therapy (SBRT)

\section{POLICY NUMBER A60110 2016}

19. Nabors LB, Portnow J, Ammirati M, et al. Central nervous system cancers, version 2. 2014. Featured updates to the NCCN Guidelines. Journal of the National Comprehensive Cancer Network: JNCCN 2014;12(11):1517-23.

20. Knisely JP, Yamamoto M, Gross CP, et al. Radiosurgery alone for 5 or more brain metastases: expert opinion survey. Journal of Neurosurgery 2010;113 Suppl:84-9. doi: 10.3171/2010.8.GKS10999

21. Sandler KA, Shaverdian N, Cook RR, et al. Treatment trends for patients with brain metastases: Does practice reflect the data? Cancer 2017;123(12):2274-82. doi: 10.1002/ cncr.30607

22. Soliman H, Das S, Larson DA, et al. Stereotactic radiosurgery (SRS) in the modern management of patients with brain metastases. Oncotarget 2016;7(11):12318-30 doi: 10.18632/oncotarget.7131 
23. Minniti G, Clarke E, Lanzetta G, et al. Stereotactic radiosurgery for brain metastases: analysis of outcome and risk of brain radionecrosis. Radiat Oncol 2011;6:48. doi: 10.1186/1748-717X-6-48

24. Keeter S KC, Dimock M, Best J, Craighill P. Gauging the impact of growing nonresponse on estimates from a national RDD telephone survey. Public Opin Q 2006;70:759-79.
25. Holbrook A KJ, Pfent A. T In: Lepkowki JM, Tucker C, Brick JM, al. e. The causes and consequences of response rates in surveys by the news media and government contractor survey research firms. Advances in Telephone Survey Methodology John Wiley \& Sons 2008:499-500.

\author{
Corresponding Author \\ Wenyin Shi, MD, PhD \\ Department of Radiation Oncology \\ Sidney Kimmel Medical College \\ Thomas Jefferson University \\ Sidney Kimmel Cancer Center \\ at Jefferson \\ 111 South 11th Street \\ Philadelphia, PA 19107 \\ P: $215-955-6700$ \\ F: 215-503-0013 \\ E: wenyin.shi@jefferson.edu
}

\section{Let's Talk About It}

Jefferson's Brain Tumor Support Group is the perfect place for patients and their loved ones to talk about living with a brain tumor. Jefferson staff members are present and available to answer any questions or concerns you may have.

Second Thursday of every month 6:30 PM to 7:30 PM

Jefferson Hospital for Neuroscience (JHN) 900 Walnut Street, 3rd Floor

Philadelphia, PA 19107

Free parking available at the JHN parking lot

If you have questions, please call

215-955-7000

RSVP is requested, but not required.

Sidney Kimmel Cancer Center Jefferson Health. $\mathrm{NCl}$ - designated

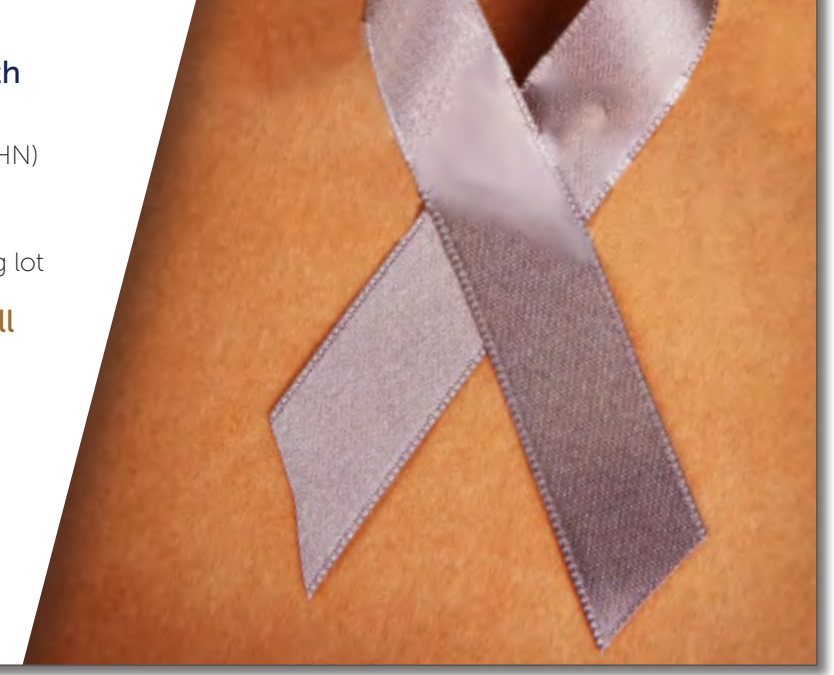

